CRÍTICA, Revista Hispanoamericana de Filosofía

Vol. XXVII, No. 79 (abril 1995): 21-45

\title{
FIDELIDAD A LOS HECHOS Y SUSPICACIA SEMÁNTICA*
}

\author{
Alberto Moretti \\ Sociedad Argentina de Análisis Filosófico \\ Universidad de Buenos Aires
}

\section{Candores}

La ingenuidad es una condición difícil de reconocer. Suele ser una forma de la costumbre y, se sabe, podemos acostumbrarnos a toda clase de injusticias, deterioros y alambicadas corrupciones. Entonces nada impide que nuestros cambios de opinión semántica sean el ir y venir de unas cuantas posiciones, frutos del olvido y la jovialidad, sostenidas con diversos grados de candor o desafío. Como quiera que sea, en estos días se considera un rasgo de ingenuidad semántica sostener una serie de creencias como las siguientes: (1) algo objetivo y, en general, independiente de la actividad mental de los seres humanos está sistemáticamente "conectado" con el lenguaje y es esencial (acaso suficiente) para entender la significatividad de las oraciones (al menos las declarativas); (2) hay esencialmente un solo tipo

* Este texto reproduce, infielmente, el contenido de la exposición oral (y de algunas de las notas que le sirvieron de base) efectuada en el XIII Simposio Internacional de Filosofía del IIF-UNAM, en agosto de 1994. Dentro y fuera del Simposio, T.M. Simpson discutió conmigo muchos de los temas tratados. Si hubiese tenido tiempo de ser más fiel a esos hechos, su presencia en este texto habría sido considerablemente mayor. Pero el texto sería otro y mejor (y mucho más infiel, en consecuencia). 
de relación entre las expresiones lingüísticas y el mundo en general, que permite aclarar el significado lingüístico (en particular, no necesitamos distinguir entre denotar una referencia y expresar un sentido); (3) las oraciones (declarativas) se refieren a, o se corresponden con, estados de cosas, hechos o entidades de algún tipo especial; (4) cuando interesa entender la conservación de la verdad en los tránsitos oracionales (digamos, el papel inferencial de las oraciones) basta con considerar las referencias de las partes suboracionales; (5) esas partes desempeñan el mismo papel semántico tanto cuando se toman las oraciones aisladamente como cuando se estudia su papel como componentes de oraciones mayores. En este contexto, parece sencillo creer que una expresión suboracional se refiere a alguna entidad mundana y que, si las oraciones también lo hacen, eso a lo que se refieran dependerá de las referencias de sus componentes.

¿Qué pues, de interés semántico, queda determinado cuando se consideran las referencias de las partes suboracionales de una oración? Su valor veritativo, se oirá responder desde Frege-Tarski hasta D. Lewis y Davidson. Pero un ingenuo de hoy preferirá decir que esas referencias determinan un hecho (tal vez uno posible o la posibilidad de uno) cuya existencia o inexistencia determinará, en su turno, un valor veritativo para la oración. El ingenuo está parcialmente de acuerdo con los doctos de la hora, pero su inocencia es tan soberbia que pretende ver más hondo que ellos. Cuando se crea, como tiende a hacer el inocente, que aquello primariamente determinado por las referencias de los componentes de una oración no es una entidad simple sino compuesta y estrechamente ligada con esa oración y sus componentes, cabrá preguntar también, en relación con (4), ¿qué es suficiente conocer de esa entidad a fin de comprender el papel inferencial de la oración? A veces quizá baste con saber que induce algún valor veritativo; en otras 
ocasiones tal vez se requiera conocer más que eso, conocer, por ejemplo, de qué manera lo induce en la oración del caso. ${ }^{l}$ Pero uno puede preguntarse — ahora en relación con (3) - por los rasgos del mundo que aparecen especialmente destacados por una oración, al margen de la preocupación por su papel inferencial. Esto es, aun cuando en ciertos contextos su importancia inferencial dependa sólo de que posea algún valor veritativo, aun entonces (pensará el ingenuo) el análisis semántico ulterior ha de mostrar un contenido mayor, dirigido hacia aspectos parciales de la realidad. Y, siguiendo (2), deseará creer que la relación originaria entre esa oración y el mundo es la que se da entre ella y ese contenido especial.

Son arduos los problemas a que conduce mantener juntas a (2) y (3), especialmente junto con algún resto de la idea (también ingenua) de que las oraciones gramaticalmente distintas nombran hechos distintos (idea que tiene el mérito de simplificar el hallazgo de los hechos nombrados por las oraciones, pero tiene demasiados deméritos). ${ }^{2} \mathrm{Y}$ sin duda es muy difícil defender una posición semántica inocente como la bosquejada antes, sobre todo cuando se insista también en (5). Pero, ya que la inocencia tiene matices, detengámonos en uno de ellos, la "tesis" (3). Distingamos, por una parte, un "uso lingüístico" de esa idea, presente cuando se piensa que las oraciones, como los nombres propios, se emplean para nombrar algo, y ese ente, o ese empleo, aclara su

1 Frege, perdida su inocencia, no creía que existieran más entidades que la verdad y la falsedad (el Ser y la Nada, si parafraseamos leibnizianamente a C.I. Lewis) como referencias de las oraciones, pero advertía la necesidad de hacer algo como "discernir partes" en esos valores, al menos para comprender su papel inferencial en ciertos casos (algunos contextos oblicuos).

2 Para el análisis de estos problemas es insoslayable el capítulo II, "De las formas relacionales a los hechos atómicos", del libro de T.M. Simpson, Formas lógicas, realidad y significado, Eudeba, Buenos Aires, 1964 (la. ed.), 1975 (2a. ed.); en adelante FLRS. 
significatividad; y, por otra parte, su "uso gnoseológico", manifiesto cuando se la entiende como la tesis de que las oraciones se corresponden con hechos y esto aclara la idea de verdad. Utilizar el concepto de verdad reporta ventajas prácticas para la comunicación fluida, pero también se puede emplear con fines teóricos, por ejemplo para aclarar la idea de conocimiento, o como pieza para mostrar de qué manera se puede conectar el lenguaje con un mundo cuya estructura se ha pensado sin intentar "adaptarla" a la estructura o función imaginada antes para el lenguaje dado. Sólo creyendo que el único empleo teórico útil de esa noción está en la explicación del funcionamiento del lenguaje e impulsando para esto alguna teoría escueta (basada, por ejemplo, en la atribución de condiciones veritativas creíbles por el hablante) puede sostenerse que, prima facie, el segundo uso sólo es una versión disfrazada o equívoca del primero. Sin este prejuicio, la segunda interpretación de (3) permite expresar una ingenuidad escindible del resto y con prosapia: la idea de que el concepto de verdad se puede aclarar en términos de una correspondencia entre oraciones y hechos; en términos de fidelidad a los hechos. Se dirá entonces, naturalmente, que una oración es verdadera si y sólo si representa un hecho existente.

\section{Suspicacia}

El joven Frege pudo adoptar durante algún tiempo una imagen inocente. Pero la tentación de los enunciados de identidad fue demasiada y socavó su respeto por (2). ${ }^{3}$ Arrojado ya del dudoso paraíso, no le fue difícil, mareado por

3 Véase G. Frege, 1892, "Uber Sinn und Bedeutung". Cito con la traducción de Bulygin y Rabossi, anotada por Simpson, en Simpson (comp.), Semántica filosófica: problemas y discusiones, Siglo XXI, Buenos Aires, 1973; cfr. pp. 3, 4 y 27. 
los contextos oblicuos, ceder también su fe en (5). ${ }^{4}$ No renegó de la idea de que las oraciones están conectadas con entidades de algún tipo, entidades que entendió nombradas por las oraciones. Pero también aquí su desconfianza semántica le dio motivo para no caer en la tentación de la inocencia. Se convenció de que toda oración (declarativa) nombra sólo una de dos cosas: la verdad o la falsedad. De aquí a creer que no hay hechos distintos correspondientes a oraciones distintas, o que sólo existe un único hecho o, sencillamente, que no existe hecho alguno, hay poco tramo. Tal fue cubierto explícitamente por C.I. Lewis luego de que A. Church se basara en aquellas reflexiones de Frege para refutar el primer largo esfuerzo semántico de Carnap.

Más tarde, Quine utilizó la estructura argumental ideada por Frege-Church en varias oportunidades. Como si esos agresores no bastasen, también Gödel, incidentalmente, ofreció colaboración en el embate. Por intermedio de Quine, esta estrategia llegó a ser altamente estimada por Davidson, quien la empleó para dos tareas. Primero para mostrar la inviabilidad de cualquier explicación del significado oracional que sólo se base en la atribución de referencias específicas a las oraciones. Y luego, directamente en contra de cualquier aclaración del concepto de verdad en términos de correspondencia entre oraciones y hechos. Consideremos este último atropello, sin examinar sus múltiples lazos con afrentas similares.

\subsection{El comienzo fregeano}

La semántica de los nombres individuales parece sencilla: sabiendo a qué se refiere un nombre como 'Martín García' estamos en condiciones de utilizarlo normalmente en

${ }^{4}$ Frege, op. cit., pp. 6 y 13. 
el discurso. Admitirlo mientras se busca una teoría sistemática fácil de creer, hace razonable investigar el resultado de extender el modelo de los nombres a otros tipos de expresiones que se destaquen, entre ellas las oraciones. ${ }^{5} \mathrm{Y}$ si es natural pensar que un nombre está conectado con un objeto al que se refiere, será natural esperar que haya algo referido por una oración.

¿A qué se refiere 'Sócrates ríe de buena gana'? Con esa oración (llamémosla $A$ ) se atribuyen extraños movimientos y sonidos inarticulados al objeto al que 'Sócrates' se refiera. De donde, si no hubiese tal objeto, no adjudicaríamos ni verdad ni falsedad a la oración. Así es que, si nos interesa el valor veritativo de $A$, deberemos presuponer que sus componentes (al menos sus nombres) denotan objetos. Y para determinar cuál es su valor veritativo tendríamos que conocer cuáles son estos objetos denotados por sus componentes, ya que no basta con suponer que existen, porque la sustitución de uno de ellos por otro al que sólo se le exija que denote algo puede modificar el valor veritativo de la oración. Supongamos, ahora, que la referencia de $A$ (no meramente el que exista algo referido por $A$ ) dependa de que sus componentes denoten algo (así como la referencia de 'El (más célebre) maestro de Platón' parece depender de que 'Platón' denote algo). Siendo así, si nos interesa la referencia de $A$ deberemos presuponer que sus componentes denotan objetos. Más aún, supongamos que esa referencia dependa de cuáles sean los objetos denotados por los componentes (así como el que Sócrates sea la referencia de 'El maestro de Platón' no sólo depende de que 'Platón' denote algo, sino también de que se refiera precisamente a Platón (o a alguien como él)). Admitamos,

5 Hay un modo más interesante, pero menos intuitivo, de alentar la idea de las oraciones como nombres individuales. Consiste en explotar la idea de los predicados como funciones; véase FLRS, p. 117. 
además, que la sustitución de un componente por alguna expresión que tenga igual referencia no cambia la referencia de $A$; vale decir, que ésta — en lo que hace al papel de sus nombres componentes - sólo depende de las referencias de esos nombres (así como la referencia de 'El maestro del maestro de Aristóteles' coincide con la de 'El maestro de Platón'). Entender $A$, por otra parte, es posible sin preocuparse por si sus componentes denotan algo y, en consecuencia, sin saber si ella misma se refiere a algo o no lo hace. ¿Cuándo, entonces, interesará la referencia de $A$ ?

Si nuestro interés cognoscitivo básico, respecto de $A$, fuese atribuirle un valor veritativo, es fácil imaginar que sólo nos interesará la referencia de $A$ como un subproducto de nuestro interés básico, originado por el hecho de que, al preocuparnos por la referencia de sus componentes, buscando su valor veritativo, cumplimos parte de la tarea para garantizar o determinar su referencia. Establecidas las referencias de los componentes, tenemos ya elementos necesarios (y tal vez suficientes) para determinar tanto la referencia de $A$ como su valor veritativo. Pero entonces, ¿por qué no simplificar la explicación, identificando la referencia de $A$ con su valor veritativo? Luego de consideraciones parecidas Frege observa: "En consecuencia nos vemos llevados a aceptar el valor veritativo de una oración como su referencia." ${ }^{\circ}$ Después de todo, el valor veritativo de $A$ cumple las condiciones mínimas para ser su referencia. En particular, satisface el requisito de inalterabilidad frente a sustituciones equirreferenciales. Y “¿qué otra cosa, sino el valor veritativo, podría hallarse que perteneciera en general a toda oración (cuando las referencias de sus componentes se consideren relevantes) y permaneciese inalterada por sus-

${ }^{6}$ Frege, op. cit., p. 11. 
tituciones del tipo indicado?". ${ }^{7}$ En estas condiciones, desde luego, o bien $A$ se refiere a la verdad o bien a la falsedad y, en general, todas las oraciones verdaderas tienen la misma referencia y todas las falsas se refieren a lo mismo. (Eso sí, verdad y falsedad difieren (pero, ¿̨en qué?).) La referencia de una oración, o bien no tiene determinaciones, o tiene todas las determinaciones representables por la totalidad de las oraciones de su mismo valor veritativo. Los objetos especificados por los componentes de una oración no tienen ningún papel especial en la caracterización de la entidad referida por la oración completa, aunque resulten necesarios para conocer cuál es esa entidad.

\subsection{Las provincias de Utah}

En 1956, A. Church ${ }^{8}$ volvió a hablar de una oración de larga fama:

(I) Scott es el autor de Waverley.

Pero (I) misma, ¿de qué habla? Parece que al menos se ocupa de una persona denotada por 'Scott' y también por 'el autor de Waverley'. Y dado que el escritor referido por la descripción anterior es el mismo que escribió veintinueve novelas que llevan el nombre 'Waverley', se aceptará, siguiendo a Frege, que (I) tiene la misma referencia que (II):

(II) Scott es quien escribió veintinueve novelas Waverley.

Considérese ahora la oración (III) (para facilitar las cosas, puede imaginarse un contexto que ante la pregunta "¿qué dijo?" relativa a (II), autorice para responder con (III) como mero cambio de énfasis),

${ }^{7}$ Ibid., p. 12.

8 A. Church, Introduction to Mathematical Logic, U.P., Princeton, 1956, pp. 24 y 25. 
(III) Veintinueve es el número de novelas Waverley escritas por Scott.

¿Será posible que alguien que entienda normalmente (II) y (III) crea que tienen distinta referencia? Entender una oración ha de implicar, seguramente, saber de qué "pretende hablar". Si, otra vez cerca de Frege, creyéramos que las referencias de (II) y (III) dependen enteramente de las referencias de sus componentes, tal vez nos dediquemos a desmenuzar sus partes semánticamente pertinentes, para comprobar si esas oraciones tienen la posibilidad de hablar de cosas distintas. Resultará entonces más o menos natural decir que (III) incluye referencias a Scott, el número veintinueve y las novelas Waverley, y atribuye a Scott cierta fecundidad monotemática. Pero, ¿no es esto todo lo que hace (II), salvo peculiaridades de estilo sin importancia temática? Se dirá tal vez que (III) atribuye algo también a veintinueve, pero eso también se puede encontrar en (II) (acudiendo a Frege de nuevo (p. ej. Begriffschrift, §3) la rotación de sujetos gramaticales se pretenderá con valor puramente enfático; compárese 'Veintinueve es el número de novelas Waverley escritas por Scott' con 'Scott es quien escribió novelas Waverley en número de veintinueve'). Nos inclinaríamos entonces a reconocer que ambas oraciones tendrán que coincidir también en su referencia global. Pero ocurre además, que el número de novelas Waverley escritas por Scott es el mismo que el número de provincias de Utah. Por consiguiente, (III) tiene idéntica referencia que

(IV) Veintinueve es el número de provincias de Utah.

Hemos obtenido, al cabo, que (I) y (IV) también se refieren a lo mismo, aun cuando sus componentes no lo hacen (la situación dista de ser excepcional; recuérdense 'El hijo (más célebre) de Sofronisco', 'El hijo de Fenareta' y 'El maestro de Platón’). No es tan fácil el tránsito desde (I) 
hasta 'Nadie estuvo en Neptuno', pero el ejemplo, y otros similares, abonan la conjetura de que todas las oraciones coincidentes en valor veritativo se refieren a lo mismo, $\mathrm{y}$ animan la tesis fregeana de que esos valores son, precisamente, los objetos a los que refieren.

2.3. Proposiciones inocentes

Carnap había publicado, en 1942, su libro Introduction to Semantics donde, entre muchas cosas, admitía esencialmente lo que ahora se enunciará con la debida imprecisión:

P.0: Todo el significado de los nombres está dado por lo que nombran.

(Escribiremos 'Ref $(n, N)$ ' para decir que el nombre $n$ refiere al objeto $N$ ).

P.1: a) Las oraciones son nombres (y entonces pueden ocupar lugares sintácticos nominales). Se refieren a proposiciones.

b) Lo nombrado por una oración (su referencia) tiene una naturaleza determinada especialmente por las referencias de sus componentes.

P.2: Los nombres correferenciales son intersustituibles.

P.3: Las oraciones lógicamente equivalentes son nombres correferenciales.

$\mathrm{Al}$ año siguiente Church, ${ }^{9}$ en su reseña del libro, desarrolló el siguiente argumento: considérense las expresiones

$$
\hat{x}(x=x .-p) ; \hat{x}(x \neq x),(\text { que se abreviará con ' } \emptyset \text { ') }
$$

y las oraciones,

(I) $\hat{x}(x=x \cdot-p)=\emptyset$

9 A. Church, "Carnap's Introduction to Semantics", The Philosophical Review, vol. LXX, 1943. 
(II) $\emptyset=\emptyset$

Supóngase que la oración ' $p$ ' es verdadera (pero no por motivos lógicos). Entonces:

(1) $p$

(2) $\operatorname{Ref}((\mathrm{I}), \hat{x}(x=x .-p)=\emptyset) ; \quad$ por P.1

(3) Ref $((\mathrm{II}), \emptyset=\emptyset)$; $\quad$ por P.1

(4) $\hat{x}(x=x .-p)=\emptyset ; \quad$ por (1)

(5) $\operatorname{Ref}((\mathrm{I}), \emptyset=\emptyset) ; \quad$ de (2) y (4) por P.2

(6) (I) y (II) se refieren a lo mismo; de (3) y (5)

(7) (I) y (II) significan lo mismo; $\quad$ por P.0 y P.1

Los dos últimos pasos son suficientes, dice Church, para mostrar que:

(8) (I) y (II) no pueden referirse a proposiciones

"puesto que las proposiciones correspondientes $\langle a(\mathrm{I})$ y (II) $\rangle$ ciertamente no son la misma en ningún sentido ordinario de la palabra 'proposición' (juna oración es lógicamente verdadera y la otra no lo es!)" ${ }^{10} \mathrm{Y}$ continúa:

(9) ' $p$ ' es lógicamente equivalente a ' $\hat{x}(x=x .-p)=\emptyset$ '

(10) ' $p$ ' y (II) se refieren a lo mismo; de (6) y (9) por P.3.

$\mathrm{Y}$ puesto que el mismo razonamiento puede llevarse a cabo con cualquier oración verdadera, y uno análogo puede construirse para las oraciones falsas:

(11) Todas las oraciones coincidentes en valor veritativo se refieren a lo mismo.

El corazón fregeano de Church le hace concluir, en una frase impetuosa, que no cabe otra posibilidad que la de los valores veritativos, como candidatos a referencia de las oraciones. Por varios motivos las proposiciones deberán

${ }^{10}$ Church, op. cit., p. 300. 
conservarse, pero su relación con las oraciones ya no podrá ser referencial. Church aconseja, por último, dejar atrás la edad inocente en que rigen P.0 y P.1, y resignarse a ser arrojados al proceloso mundo de Frege.

\subsection{La caída del realismo}

En "Truth and Meaning" Davidson ${ }^{11}$ utiliza el argumento de Church con una finalidad semejante a la de éste: si las oraciones son nombres y su significado es su referencia, entonces, si se adoptan dos "supuestos razonables", todas las oraciones con igual valor veritativo son sinónimas. Por ende, para seguir siendo razonables, conviene no creer que el significado de las oraciones sea su referencia o, más drásticamente, descreer de que siquiera tengan referencia. Las dos suposiciones aludidas son, nuevamente, la sustituibilidad de términos correferenciales dentro de un nombre (P.2) y la correferencialidad de oraciones lógicamente equivalentes (P.3). El argumento involucra las oraciones ' $\hat{x}(x=x \cdot p)=\hat{x}(x=x)$ ' '(que llamaremos $A)$ $\mathrm{y}{ }^{'} \hat{x}(x=x \cdot q)=\hat{x}(x=x)$ ' (que llamaremos $\left.B\right)$, bajo la condición de equivalencia de valores veritativos entre ' $p$ ' y ‘ $q$ '. Así (usando ' $L$-equiv' para indicar equivalencia lógica):

(1) $p \equiv q$

(2) ' $p$ ' $L$-equiv $A$; por el principio de identidad de conjuntos y la ley ' $(x=x \cdot p) \equiv p$ '

(3) La referencia de ' $p$ ' = La referencia de $A$; de (2) por P.3

(4) $\hat{x}(x=x \cdot p)=\hat{x}(x=x \cdot q)$; de (1) por identidad de conjuntos

(5) La referencia de $A=$ La referencia de $B$; de (4) por P.2

(6) La referencia de ' $p$ ' = La referencia de $B$; de (3) y (5) por transitividad

11 D. Davidson, "Truth and Meaning", Synthèse, 17, 1967. 
(7) $B L$-equiv ' $q$ '; por identidad de conjuntos y la ley ' $(x=$ $x . q) \equiv q$

(8) La referencia de $B=$ La referencia de ' $q$ '; de (7) por P.3

(9) La referencia de ' $p$ ' = La referencia de ' $q$ '; de (6) y (8) por transit.

Por consiguiente: si ' $p$ ' y ' $q$ ' tienen igual valor veritativo entonces tienen igual referencia. $\mathrm{Y}$ si el significado es la referencia, son sinónimas.

Dos años después, ${ }^{12}$ Davidson estudia la viabilidad de una explicación correspondentista de la verdad, comenzando por la más popular: la que descansa en la noción de hecho (mencionada en la sección 1). Su conclusión es negativa. Si la correspondencia ha de sostenerse, no será una relación entre oraciones y hechos. Porque no se conoce ninguna aclaración de la idea de hecho que no se apoye en la de verdad, generando un círculo lamentable. Por otro lado, la predicación de verdad no parece eliminable, en tanto que la mención de hechos no sólo lo parece sino que también es inútil. Porque, ¿cómo se individualiza un hecho?, ¿cómo se diferencia un hecho de otro? Podría suponerse que las oraciones se corresponden con hechos y que (al menos algunas) oraciones distintas individualizan hechos distintos. Pero esto, asegura Davidson, no es cierto. Basta, para entenderlo, con aceptar que la descripción 'El hecho de que $p$ ' se refiere al mismo hecho que la descripción 'El hecho de que $q$ ' siempre que: (a) ' $p$ ' y ' $q$ ' sean lógicamente equivalentes o, (b) sólo difieran por la presencia de términos singulares correferenciales. (Llamemos $S$ a este principio). Porque, ahora, supongamos que ' $p$ ' y ' $q$ ' sean oraciones verdaderas cualesquiera (y que ' $\mathrm{D}$ ' y 'Corr' abrevian 'Diógenes' y 'corresponde a' respectivamente), entonces:

12 D. Davidson, "True to the Facts", The Journal of Philosophy, 66, 1969. 
(1) ' $p$ ' Corr El hecho de que $p$

(2) ' $p$ ' $L$-equiv ' $(7 x)(x=D \cdot p)=(7 x)(x=D)$ '

(3) ' $p$ ' Corr El hecho de que $(7 x)(x=D \cdot p)=(7 x)(x=D)$; por $\mathrm{S}(\mathrm{a})$

(4) (\urcorner $x)(x=D \cdot p)=(\urcorner x)(x=D \cdot q)$

(5) ' $p$ ' Corr El hecho de que $(7 x)(x=D \cdot q)=(\neg x)(x=D)$; de (3), (4) por $\mathrm{S}(\mathrm{b})$

(6) ' $q$ ' $L$-equiv ' $(7 x)(x=D \cdot q)=(7 x)(x=D)$ '

(7) ' $p$ ' Corr El hecho de que $q$; de (5) y (6) por $\mathrm{S}(\mathrm{a})$.

Y agrega, "Puesto que además del recurso a la correspondencia no se ha propuesto ninguna manera de distinguir hechos, y esta vía (test) no permite descubrir ninguna diferencia, podemos interpretar el resultado de nuestro argumento como una prueba de que existe tan sólo un hecho." 13 Davidson reconoce que algunos podrán imaginar una noción de hecho que pudiese autorizar el rechazo de $S$ pero, según opina, de nada servirá para la tarea de aclarar la idea de verdad: "Supongamos que, dejando el fuego de la extensionalidad por las brasas de la intensión, distinguimos los hechos tan finamente como los enunciados. Naturalmente, no todo enunciado tiene su hecho; sólo los verdaderos. Pero entonces, a menos que encontremos otra manera de indicar (pick out) hechos, no podemos esperar explicar la verdad apelando a ellos." 14

Veinte años después, Davidson había llegado más lejos. ${ }^{15}$ Ahora no sólo la idea de hecho, sino la propia idea de correspondencia le parece disuelta en las corrosivas aguas del argumento de Church. Perdidos los hechos, la correspondencia buscaba refugio en el nexo referencial entre expre-

13 Davidson, op. cit., p. 753.

14 Ibid.

15 D. Davidson, "The Structure and Content of Truth", The Journal of Philosophy, vol. LXXXVII, 1990. 
siones suboracionales y algo en el mundo. Aparecía transformada en la relación tarskiana de satisfacción. Pero, bien mirada, esta relación tampoco garantiza especificidad para el vínculo de las oraciones (verdaderas) con el mundo ya que todas ellas son satisfechas por lo mismo y, por otra parte, las entidades con las que se asocian las expresiones suboracionales (las secuencias de objetos) son de una "naturaleza contraintuitiva y amañada". Y, de todos modos, la noción de correspondencia que se necesita para elucidar la idea de verdad es la de una relación entre los objetos de los que se predica (las oraciones) y un conjunto de entidades que fundamentan esa predicación. Pero el argumento de Frege-Church muestra "que nada hay de interesante o instructivo a lo que puedan corresponder las oraciones", ${ }^{16}$ ya que todas refieren a todo. Pero si sólo hay una entidad a la que puedan corresponder las oraciones "la relación de correspondencia carece de interés $[\ldots]$ puesto que $[\ldots]$ se puede hacer colapsar en una propiedad simple [...]'s se corresponde con los hechos' puede leerse, menos equívocamente, como 's es verdadera" ". ${ }^{17}$

Junto con la idea de correspondencia cae la idea de representación y la idea misma de realismo. "La concepción realista de la verdad, si tiene algún contenido, debe basarse en la idea de correspondencia, correspondencia en tanto aplicada a oraciones o creencias o emisiones, entidades de carácter proposicional; y tal correspondencia no puede hacerse inteligible." 18 La de correspondencia "es una idea sin contenido"19 y la concepción realista de la verdad es "en última instancia ininteligible". ${ }^{20}$

16 Davidson, op. cit., p. 303

17 Ibid.

18 Ibid.

19 Ibid.

20 Ibid., p. 298. 


\section{Revelaciones}

No es difícil imaginar los comentarios reactivos de un ingenuo enfrentado al recelo de sus críticos. Anotaremos rápidamente algunos de ellos $\mathrm{y}$, al hacerlo, se verá que el periplo del esquema argumental de la sección 2 , en cuanto dirigido contra el correspondentista de la sección 1, tuvo un comienzo algo vacilante con Frege, un periodo firme pero inocuo en manos de Church y Quine, y una etapa última e incauta.

Suponiendo que los ejemplos y esbozos habituales brindan una mediana comprensión de la diferencia entre materia y forma de una oración, queda claro que, para los objetivos de la lógica formal, interesará la capacidad de determinar todos los detalles de la forma de una oración - aunque no todos hagan falta en contextos particulares - y apenas importará su materia específica. Pues, así se expone, lo que se busca es garantizar que las inferencias no puedan conducir, en razón de su forma, a creencias erróneas sobre el mundo si es que las premisas brindan genuino conocimiento sobre él (para lo cual frecuentemente basta con un análisis formal parcial). De las oraciones involucradas, además de su forma, sólo importará que tengan materia y que, por tanto, acierten o yerren acerca del mundo. Frente a una oración, considerarla o bien verdadera o bien falsa, resume entonces, plenamente, ese escueto interés que la lógica formal (aplicada) tiene en la materia oracional. Por así decir, importa la pretensión de que representa, pero no qué representa. Cuando la meta es la validación de ciertas inferencias (como lo era para Frege, hacia 1892) o, alternativamente, el descubrimiento de oraciones cuya verdad es independiente de su materia específica, la atribución de valor veritativo a una oración puede ser un fin en sí mismo. Pero fuera de la investigación de formas, cuando lo buscado sea información específica, el objetivo básico pasará a ser la materia de 
una oración, y atribuirle valor veritativo un indicador de dónde está, en cuáles oraciones, la información específica deseada. Si tratásemos de explicar la función semántica de una oración con el modelo de los nombres simples, buscaríamos algo que fuese su referencia. $\mathrm{Y}$ si esa oración nos interesara no sólo por su forma sino, prioritariamente, por su contenido, entonces no nos bastaría con atribuirle un valor veritativo, ya que eso no la distinguiría suficientemente de otras oraciones que, es natural pensar, transmiten diferente información. No seríamos llevados a aceptar, a pesar de Frege, que su valor veritativo es su referencia. Los valores veritativos satisfacen, ya vimos, los requisitos formales mínimos para ser referencia de oraciones. Pero no son los únicos que lo hacen. ¿Qué otra cosa podría hallarse?: los hechos específicos, responderá con naturalidad un espíritu inocente. Quitemos ahora la pretensión de, con este inocente "descubrimiento", aclarar completamente el papel semántico de una oración, y reencontraremos la "tesis" (3) de la sección 1 cuando sólo afirma la existencia de una conexión entre oraciones y ciertas entidades del mundo (distintas de - aunque relacionadas con ellas - las que pudieran asociarse con sus componentes suboracionales). Evidentemente, Frege no demostró que todas las oraciones verdaderas refieren a lo mismo, sino que dio motivos para hacer razonable la hipótesis de que los valores veritativos son la referencia de las oraciones, hipótesis de la que se deduce aquel aserto. Que la verdad no es lo único inalterable bajo las sustituciones equirreferenciales lo muestra el que también lo son la clase unitaria de la verdad y la clase unitaria de esta clase, etc. O, como Simpson señaló hace tiempo, la clase de equivalencia respecto de la relación de igualdad en valor veritativo y cada uno de los términos de la sucesión de clases unitarias a partir de ésta. ${ }^{21} \mathrm{~A}$ lo sumo,

${ }^{21}$ Simpson, FLRS, 2a. ed., Apéndice I. 
se dirá que los valores veritativos son las entidades más sencillas de entre aquellas que cumplen con los requisitos mínimos para las referencias de las oraciones. Pero si se imponen otros requerimientos, vinculados con funciones teóricas que se espera cumplan las entidades asociadas a las oraciones (por ejemplo, aclarar la noción de verdad) y se resta el requisito de que esa asociación explique enteramente la significatividad oracional, la elección fregeana pierde su encanto.

Si las oraciones se correspondieran con hechos específicos, pero no suministrasen indicación alguna de con cuáles se corresponden ( $y$, todo parece señalar, no hay muchos otros sitios donde encontrar indicios pertinentes), entonces la idea misma de esa asociación se tornaría dudosa. Podrán admitirse casos extraños, pero la norma ha de pedir que los objetos referidos por los componentes suboracionales integren (de algún modo directo) la entidad referida por la oración; y ha de impedir que dos oraciones que (vía sus componentes) no remitan a entidades comunes, coincidan en referencia. Entonces aparece Church y trata de convencernos de que 'Scott es el autor de Waverley' se refiere a lo mismo que 'El número de provincias de Utah es veintinueve'.

Inicialmente pueden decirse dos cosas sobre su argumento. La primera, sobre lo que Simpson denominó "un salto mortal" de Church: el pasaje de (II) a (III) (cfr. subsección 2.2). ${ }^{22}$ Debe observarse que 'veintinueve' ocupa el lugar de un término singular en (III), pero no así en (II). Allí su figuración es adjetival, en un lugar entonces más apropiado para un término general. Si en algún sentido (II) hablara del número veintinueve sería, parece, un sentido diferente al ejemplificado en (III). Al menos para la comprensión semántica ordinaria, que es la que está en juego en el argu-

${ }^{22}$ Simpson, FLRS, 2a. ed., p. 100. 
mento de Church. El asunto es delicado ${ }^{23}$ por ejemplo, hay quienes no creen en la existencia de números y sólo aceptan el uso adjetival de los numerales, pero aun así podría sostenerse que formulaciones como (III) son recursos prácticos para aplicar la aritmética como regla inferencial, aduciendo que (III) y (IV) son teóricamente dispensables en favor de versiones donde 'veintinueve' sólo es un adjetivo. Admitir lo delicado del asunto significa reforzar la idea de que el sentido común semántico no alcanza para garantizar la preservación de la referencia desde (II) a (III) y viceversa (ambas vías deberían quedar "intuitivamente" garantizadas). Es tentador preguntar, para convencer al hablante normal, si se podría aceptar que una fuese verdadera y la otra no, esperando una razonable negativa. Sin embargo, esto no aporta nada para dirimir la cuestión, que era, precisamente, la de si hay motivos para identificar igualdad de referencia con igualdad de valor veritativo. La segunda observación concierne a la diferencia en el análisis de los términos singulares, en el pasaje de (I) a (II) (y de (III) a (IV)) por un lado, y en el paso de (II) a (III) por otro lado. Si se aplica a la relación entre (I) y (II) la misma clase de reflexión usada para sugerir la correferencialidad de (II) y (III), se verá que (II) habla de algo más que (I): el número veintinueve o, al menos, más de una novela Waverley. Sabemos que esta diferencia no necesariamente conduce a una diversidad de referencia global, pero la sugiere y, de cualquier modo, la certeza (o la convicción suficiente) de correferencialidad no surge del mero comprenderlas normalmente (como requiere el argumento). Barwise y $\mathrm{Perry}^{24}$ han sostenido que en la secuencia (I)-(IV) se fluctúa indebidamente entre dos

${ }^{23}$ Ibid., cap. IX.

${ }^{24}$ J. Barwise y J. Perry, "Semantic Innocence and Uncompromising Situations", en French, Uehling y Wettstein (comps.), Midwest Studies in Philosophy, vol. 6, Minneapolis, 1981. 
modos de interpretar las descripciones definidas presentes en el argumento. Al modo de Frege en (I)-(II) y (III)-(IV), y al modo de Russell en (II)-(III). Según el primero, sólo el objeto denotado por la descripción completa es un objeto del que pueda decirse también que la oración es acerca de él. Con el otro enfoque, deben contarse los demás objetos y propiedades que estén asociados con componentes de la descripción. La observación parece básicamente correcta, a pesar de que no se excluye explícitamente la intervención de motivos que justificasen el giro interpretativo, ni se dan razones generales, independientes de la generación del problema, para considerar que la interpretación normal es la uniforme. La sensación de perplejidad ante la aparente coincidencia referencial podría ser, para un hablante inocente, más fuerte que la sorpresa por tener que uniformar la interpretación de las descripciones, dándole suficiente motivo para hacer lo último antes que aceptar lo primero.

Las reflexiones informales de Frege y Church sugieren, aunque no alcanzan para sostenerla, la conclusión de que la igualdad de valor veritativo implica igualdad de referencia. También sugieren el argumento más general y preciso que Church formuló en su comentario a Carnap, y que, de ser sólido, proporcionaría una prueba de esa conclusión. En su versión original el razonamiento permite fundar tres tesis: las que en la subsección 2.3 se llamaron (8) y (11) y la de que las referencias de las oraciones son los valores veritativos. La tercera, estrictamente, es un non sequitur, pero las anteriores son eficaces para quitar crédito al conjunto de premisas carnapianas contra el que se dirigen. Como es habitual, cuántas de esas premisas se eliminen o sustituyan no viene determinado por el argumento. Imaginemos alguien para quien P.0 es indiferente, pero tiene interés en algo como P.1 - hay entidades específicamente vinculadas con las oraciones (llamémoslas hechos) — debido a 
que espera, con eso, echar luz sobre la idea de verdad. Ese individuo, a diferencia de Church (y del propio Carnap), buscará motivos para rechazar P.2 o P.3 y mantener P.l.

En una ocasión Quine usó el esquema argumental de Church para obtener una conclusión diferente que vale la pena recordar ahora. ${ }^{25}$ Supóngase, propone Quine, que ' $F$ ' remite a un contexto dentro del cual pueden sustituirse términos singulares correferenciales ( $F$ es referencialmente transparente) y oraciones lógicamente equivalentes. Considérese además que la oración verdadera ' $p$ ' figura en $F$ y que ' $p$ ' es materialmente equivalente a ' $q$ '. Por otra parte, se tiene que ' $p$ ' es lógicamente equivalente a ' $\hat{x}(x=x .-p)=\emptyset$ ' y que ' $q$ ' es lógicamente equivalente a ' $\hat{x}(x=x .-q)=\emptyset$ '. En consecuencia,

(1) $F p$

(2) $F(\hat{x}(x=x .-p)=\emptyset)$ por sust. de lóg. equiv.

(3) $\hat{x}(x=x \cdot-p)=\hat{x}(x=x \cdot-q)$

(4) $F(\hat{x}(x=x .-q)=\emptyset)$ por sust. de idénticos

(5) $F q$ por sust. de lóg. equiv.

Por tanto, concluye Quine, en $F$ vale la sustitución de oraciones materialmente equivalentes, es decir, $F$ es extensional. De modo que si se tienen razones para encontrar inaceptable el tránsito desde (1) hasta (5) respecto de cierto $F$, deberá rechazarse el supuesto inicial acerca de la sustitutividad en ese contexto y admitir que $F$ no es extensional. Reemplazando ' $F$ ' por 'Ref $(\ldots, \ldots)$ ' o por '... Corr...' o por 'El hecho de que...' y mutatis mutandis, reaparece el argumento de Church o el de Davidson reproducidos en las subsecciones 2.3-2.4. Por ende, un defensor de

25 W. Quine, "Three Grades of Modal Involvement", Proceedings of the XIth International Congress of Philosophy, vol. 14, Amsterdam, 1953. También en su The Ways of Paradox, U.P., Harvard, 1976. 
la correspondencia entre hechos y oraciones, al encontrar inaceptable la inferencia de (1) a (5) respecto de 'Ref (..., ... )' o '... Corr...' o 'El hecho de que...', concluirá que se trata de contextos no extensionales donde no podrán sustituirse los términos singulares correferenciales, o las oraciones lógicamente equivalentes, o ambos. Desde luego, esto puede tener sin cuidado a quien sólo quiera utilizar un lenguaje puramente extensional para efectuar aclaraciones conceptuales. Excepto, naturalmente, que se ponga en cuestión (como lo merece) la razonabilidad de semejante estrategia para el abordaje de todo problema conceptual. Para confirmar su posición, el devoto de los hechos tratará de hallar razones independientes que impidan la aplicación de los principios de sustitución que conducen al problema. Y encontrará algunas.

Observará sin duda que esos principios garantizan la preservación de la verdad a pesar de cierto tipo de sustituciones, pero no puede usárselos, sin petitio principii, como si también aseguraran la conservación de la referencia. ¿Por qué la sustitución de oraciones lógicamente equivalentes (SLE) tendría esa propiedad? Tal como se la suele entender, la SLE se aplica, precisamente, en oraciones de las que basta saber que, por razones puramente formales, coinciden en valor veritativo. Les está permitido diferir en cualquier otro aspecto de sus contenidos. Respecto de muchos contextos interesantes esa posible diferencia no afectaría su comportamiento inferencial. Pero en otros (por ejemplo, algunos contextos oblicuos) la situación será la opuesta (y hasta promovería la búsqueda de recursos adicionales para descubrir aspectos formales que estuviesen "latentes" en el contenido semántico total).

Así como Church apeló a "cualquier noción ordinaria de proposición” para mostrar que de (1)-(3) de la sección 2.3, se sigue que las proposiciones no pueden ser los designata de las oraciones, así también nuestro ingenuo acudirá a 
cualquier noción ordinaria de hecho correspondiente a una oración para cuestionar el uso de SLE en el argumento de Church. En efecto, será difícil hacerle admitir que oraciones como 'Atila es Atila', 'Gandhi es Gandhi', 'Gandhi es la persona en quien ahora estoy pensando' y 'Llueve o no llueve' hablan de, o se corresponden con, lo mismo. De igual modo se negará a creer que oraciones del tipo de ' $F a$ ' y ' $F a . b=b$ ' remiten al mismo hecho sólo porque pudieran ser lógicamente equivalentes. Tal vez, ' $\hat{x}(x=x .-p)=\emptyset$ ' $\mathrm{y}{ }^{\prime}-p$ ' sean lógicamente equivalentes, pero una depende de que ' $\emptyset$ ' denote algo y la otra no depende de esa condición. Para el correspondentista no se ven razones (al menos no se le han dado en esta ocasión) para aceptar este empleo de SLE. ${ }^{26}$

Tampoco la sustitución de términos singulares correferenciales (SI) tiene que ser admitida sin crítica. Están disponibles los recursos ofrecidos por la reducción, al modo russelliano, de buena parte de ellos (si no de todos) y la doctrina de los nombres genuinos como designadores rígidos, que posibilitan el bloqueo del argumento, al menos en un número suficiente de tipos de casos. Por ejemplo, obligando a reformular ciertas premisas mediante la eliminación de las descripciones que aparecen explícitamente, no reconociéndoles carácter de nombres genuinos, únicos sobre los que cabe usar SI.

No sólo SLE, como tal, es cuestionable en relación con la referencia de las oraciones; hasta su aplicación y, con eso, la validez formal del argumento, merece reparos. Orayen ${ }^{27}$

26 El argumento de Church necesita SLE para obtener la conclusión general. Con SI concluye (8) que depende de las características particulares de (I) y (II) (que hacen más o menos aceptable que se refieran a lo mismo). En cambio el de Gödel, en su artículo para el volumen Schilp sobre Russell (1944) no usa SLE. Pero también emplea premisas discutibles.

27 En una exposición hecha en la versión de 1984 de este mismo 
hizo notar que ' $p$ ' no es (en el sentido habitual) lógicamente equivalente a ' $\hat{x}(x=x \cdot-p)=\emptyset$ ' ni a ' $(\neg x)(x=D \cdot p)=$ $(\imath x)(x=D)^{\prime}$ ni a ' $\hat{x}(x=x \cdot p)=\hat{x}(x=x)^{\prime}$ a menos que $\emptyset \mathrm{y}$ $D$ y la clase universal existan, pero por razones puramente lógicas. Es difícil creer eso de Diógenes y es incómodo creerlo de la clase vacía o de la universal. Sin audaces tesis metafísicas a su favor, la existencia de Diógenes es contingente. Y si el tímido compromiso de la lógica elemental con la existencia de individuos ya perturba las aspiraciones de la lógica formal, mucho más lo hace la presunción de existencia de individuos especiales, y hasta extraños, como $\emptyset$ y la clase universal.

Los comentarios efectuados hasta aquí son suficientes para concluir, como mínimo, que se necesita explicitar más razones que el argumento Frege-Church para convencerse, como quiere Davidson, de la ininteligibilidad de la explicación correspondentista tradicional de la verdad, o de la vacuidad explicativa en general de la noción de hecho. En uno los textos considerados, Davidson desliza un motivo adicional para desesperar de los hechos, cuando alega que, si para individualizar hechos sólo contamos con la atribución de verdad a las oraciones, entonces no es legítimo explicar la verdad en términos de hechos. ${ }^{28}$ Sin embargo, el punto merece más elaboración. ¿De qué carácter son los criterios de identidad que se solicitan? Si se representa russellianamente un hecho ${ }^{29}$ por, digamos $\langle R, a, b\rangle$ y se lo piensa como algo distinto de la oración ' $R a b$ ', ¿hasta dónde importaría, para insistir en la existencia de $\langle R, a, b\rangle$, el que sólo siendo capaces de considerar verdadera a ' $R a b$ ' estuviésemos en

Simposio que, lamentablemente, no fue publicada y cuyo contenido me ha llegado por tradición oral.

28 En "True to the Facts", p. 753.

29 Para que la tarea no parezca sencilla deben consultarse especialmente los $\S \S 8-10,13,14$ y 61 de FLRS. 
condiciones de reconocer la existencia de $\langle R, a, b\rangle$ ? De otro modo, reconocer la existencia de $\langle R, a, b\rangle$ puede ser inseparable de reconocer la verdad de ' $R a b$ ', pero esto no significa que lo reconocido sea lo mismo. Algunos insistirán en que es porque reconocemos la existencia de $\langle R, a, b\rangle$ que reconocemos la verdad de ' $R a b$ '. Para ejemplificar, pensarán en hechos de los cuales quepa suponer que son perceptuales, y recordarán que la mera percepción de ' $R a b$ ' no alcanza para captar su valor veritativo, o asignárselo (salvo leyes lógicas), pero es suficiente observar $\langle R, a, b\rangle$ para tener buenas razones para creer que existe. La blancura de la nieve hace verdadera 'La nieve es blanca', pero no es obvio que (ver) su blancura sea lo mismo que (ver) la nieve o la blancura. Y aducirá a tal efecto que sin apelar a hechos, no puede decirse de modo general qué es lo que verifica (en sentido óntico y no epistémico) una oración. Agregando que, para comprender mejor la relación entre lenguaje y realidad, se requiere decirlo y no sólo mostrarlo mediante la generación tarskiana de condiciones veritativas. Sin duda es irritante, para un esforzado extensionalista que además tiene ante sí el instrumental tarskiano para analizar el concepto de verdad, oír decir que los hechos aclaran la verdad pero que, para hablar de ellos, hay que restringir la validez de fértiles principios de la lógica usual o hay que abrir paso a axiomas especiales sobre entidades y relaciones de vida penumbrosa. Buena parte de la cuestión depende de cómo se interprete y cuánto satisfaga la elucidación tarskiana. Asunto que tiene sus meandros. Y, por cierto, el mundo puede ser más oscuro que lo deseable para quien quiera ver claro pero muy pronto. 